\title{
Binary Logistic Regression Analysis of Identifying Demographic, Socioeconomic, and Cultural Factors that Affect Fertility Among Women of Child bearing Age in Ethiopia
}

\author{
Desalegn Dargaso Dana \\ Department of Statistics, College of Natural and Computational Sciences, Wolaita Sodo University, Wolaita Sodo, Ethiopia
}

\section{Email address:}

desdargaso@gmail.com

\section{To cite this article:}

Desalegn Dargaso Dana. Binary Logistic Regression Analysis of Identifying Demographic, Socioeconomic, and Cultural Factors that Affect Fertility Among Women of Child bearing Age in Ethiopia. Science Journal of Applied Mathematics and Statistics.

Vol. 6, No. 3, 2018, pp. 65-73. doi: 10.11648/j.sjams.20180603.11

Received: March 26, 2018; Accepted: April 12, 2018; Published: June 1, 2018

\begin{abstract}
Fertility is one of the elements in population dynamics that has a significant contribution towards changing population size and structure overtime. The aim of objective of this study is to identify Demographic, Socio-economic, and Cultural factors that affect Fertility level among women of childbearing age in Ethiopia. The data for this study were taken from Ethiopia Demographic and Health Survey conducted in 2011 (EDHS2011). For modelling purpose binary logistic regression was used and data were analyzed using SPSS Version16. The total number of women in childbearing age is based on 10,897 women who have at least one child and whose age ranges from 15 to 49 years. Among these, 8130 (74.6\%) reside in rural areas where as 2767 (25.4\%) reside in urban hubs. Among those individuals 64.2\% were currently not working and the remaining $35.8 \%$ of the respondent were categorized under currently working group. In relation to age at first Cohabitation, about $37.7 \%$ of individuals were fail under $15-17$ interval of age category and $34.5 \%$ of respondent were greater than or equal to 18 years old. The majority of individuals were married $8621(79.1 \%)$, followed by divorced and living with partner (716 (6.6\%) and living with partner 588 (5.4\%) respectively). In the analyses, all the variables Region, women educational level, wealth index, husband's/partner's educational level, marital status, age at first cohabitation and age in 5-years group were found to have significant effect on total number of child ever born at significance level of 5\%. From the fitted logistic regression model, the estimates odds ratio displayed in table 5, for the variable region reference category is Addis Ababa. The value of the odds ratio $\exp (\widehat{\beta})=1.384$, for region that the odds of having TCEB greater than or equals to five children for Tigray region is have $38.4 \%$ more than those individuals in Addis Ababa $(\mathrm{OR}=1.384$, C.I $=1.055-1.810)$ and its effect is statistically significant.
\end{abstract}

Keywords: Fertility, Total Children Ever Born, EDHS, Binary Logistic Regression Analysis

\section{Introduction}

Fertility is one of the elements in population dynamics that has a significant contribution towards changing population size and structure overtime. Fertility may be defined as the actual reproductive performance of a woman. "Fertility rate" is the number of children born per couple, person or population. Fertility rate is highest in sub-sharan Africa than any parts of the world, mainly due to strong kinship networks and high economic and social values attached to children [1].

Data collected from 39,902 women of child bearing age group (15-49) years to examine spatial patterns and determinant so fertility levels among women of child bearing age in Nigeria using NDHS (Nigeria Demographic and Health Survey) data. In the NDHS 2013 data, about 38,522 individuals were interviewed out of 40,320 households selected. Negative binomial distribution was used to investigate modeled fertility patterns using then number of children ever born. In the analysis, women of respondent categorized under child bearing age interval (15-49) who 
were follower of Islamic religion (mean $=-0.031, s d=$ 0.010 and $a 95 \% C I=-0.051$ to -0.012 ) were more likely to have children than those who were follower $s$ of traditional religion (who had no religion at all). In relation to marital status, women who are living with partners/married had more children compared with respondents categorized under other group. There is negative relationship between age of respondent and fertility pattern that means when age of women of child bearing age highly developed, then fertility pattern decreased [2].

A study done in East Africa on Variations in Desired Family Size and Excess Fertility, the result obtained from descriptive statistics focusing on excess fertility which is defined in reference and actual fertility and excluding demographic factors like mortality shows that there are variations of preferred fertility in terms of ultimate number of children; it appears clearly that East Africa countries such as Kenya, Uganda, Tanzania and Rwanda do not have the same attitude toward fertility and within the same country different communities have different aspirations regarding family size. Of the above mentioned East Africa countries, Rwanda has lowest and Kenya has highest diversity of fertility preferences according to either socio-economic or sociocultural factors that determines communities of interest, mainly educational level (categorized as no education, Insc. Primary, Comp. primary, secondary and above) and religion (categorized as Catholic, Protestant, Muslim and others). In relation to religion, Christians desire nearly a half number of children desired by that of children desired by Muslims ( 6.7 children for Muslim and 3.8 children for Protestant) where as in Rwanda Christians desire more than Muslims desire. In Tanzania Muslim prefer on more children than Christians and in Uganda there is no significant difference among religious community (5.3 and 5.2 children for Muslims and Christians respectively). Based on wealth index, individuals categorized under poorest status of life have higher chance of bearing children in both Christian and Muslim religion of East Africa countries. In the analysis of binary logistic regression, if women have 3 to 5 children than if she has more than or equals to six, then the effect of an extra children on excess fertility is greatly higher [3].

Ethiopia is one of the sub-Saharan African countries where high and persistent fertility rate has been seen for a long period of time. Although a slight decreasing trend has shown from year to year, it is still high as compared to developed nations. An assortment of reasons was mentioned for the reasons that kept the fertility rates still high in Ethiopia. Poverty, war and famine, low level of education, economic status and less autonomy of women and traditional barriers were usually mentioned as a reason for this persistent and high fertility rate in Ethiopia [4].

As the investigation was unmatched case-control study, sample size was calculated by taking into account the major determinant. In this regard, a minimum detectable OR (Odds Ratio) of 2 for under five mortalities among cases as compared to controls, a $5 \%$ level of significance (two-sided), a power of $80 \%$ and a two to one allocation ratio of controls to cases $(2: 1)$ were assumed. The mean number of children ever born (CEB) alive for older women (age 40-49 years) who are nearing the end of their reproductive period to be 7.26 from parity of 1 to 12 because the mean number of children ever born to older women, who are nearing the end of their reproductive period, is an indicator of average completed fertility. The TFR and the mean number of children ever born for women age 40-49 years would be expected to be similar. The median age at first sex and marriage was 17.0 and 17.0 for both high fertile group and low fertile group, respectively. The prevalence of important factors to be studied, which is the proportion of married women who have an experience of under-five mortality among the low fertile group, is assumed 29.7\% [5].

\section{Statement of the Problem}

Human fertility is a function of a variety of factors. They are broadly classified into proximate direct and indirect factors. The proximal factors are bio-behavioral factors known to be the intermediate determinants are the biological, reproductive and attitude factors through which the indirect determinants must devour to affect fertility and affect fertility directly, while the later, distal determinants are socio-cultural factors which consist of socio-economic and demographic factors affect fertility indirectly through affecting the biobehavioral factors. It is also a complex variable affected by multiple factors. Most studies in developing countries have put emphasis on the role of demographic, socio-economic, and cultural factors in determining difference in fertility and also the impact of this factor on fertility. The specific nature of the determinant of fertility is intricate and complex. While, fertility behavior influences population growth, which has consequences on resources, employment situation, health and other social facilities and saving and investment, in turn, such consequences have great bearing on socio-economic variables that affect fertility behavior. Socio-economic factors are in turn affected by demographic factors. These factors directly and indirectly affect the interaction process. Socio-economic variables may not directly influence fertility but they may influence fertility indirectly [6]. The method of factors affecting fertility is that intermediate variables influence fertility directly, while socio-economic and environmental variables affect fertility indirectly through intermediate variables. Some of these factors could be literacy status, occupation, religion, child birth-death ratio, wealth status, place of residence, household headship, contraceptive use, region, reproductive life span, age at first marriage and desired number of children. This study attempts to examine the effects of some selected demographic, socioeconomic, and cultural factors have an impact on fertility in the Ethiopia context.

\section{Objectives of the Study}

\subsection{General Objectives}

The general objective of this study is to identify Demographic, Socio-economic, and Cultural factors that 
affect Fertility level among women of childbearing age in Ethiopia.

\subsection{Specific Objectives}

1) To identify the factors which have significant effect on the fertility of the respondent.

2) To develop statistical model that predicts the fertility among women of childbearing age based on knowledge of the identified factors.

3) To provide information based on this study to researchers and policy makers.

\section{Data and Methodology}

\subsection{Source of Data}

This research was utilized the 2011 Ethiopian Demographic and Health Survey (EDHS) data conducted by Central Statistical Agency (CSA) in 2011 [7]. The survey is the third comprehensive and nationally representative population and health survey. The 2011 Ethiopian Demographic and Health Survey is designed to provide estimates for the health and demographic variables of interest for the following domains; Ethiopia as a whole; urban and rural areas of Ethiopia (each as a separate domain) and 11 geographic areas ( 9 regions and 2 city administrations) and it was a nationally representative survey of women aged 1549 from 17,817 households from 624 clusters (187 urban and 437 rural) areas throughout Ethiopia. Multistage cluster sample based on the 1994 Population and Housing Census sample frame and was designed to obtain information on the basic indicators of the health and demographic variables. it includes all geographic areas (nine regions namely: Tigray, Affar, Amhara, Oromiya, Somali, Benishangul-Gumuz, Southern Nations, Nationalities and Peoples (SNNP), Gambela and Harari regional states and two city administrations: Addis Ababa and Dire Dawa). In this data sample was selected using a stratified, two-stage cluster design and EAs were the sampling units for the first stage. The sample included 624 Enumeration areas (EAs), 187 in urban areas and 437 in rural areas.

All women age 15-49 who were either permanent residents of the households in the 2011 EDHS sample or visitors present in the household on the night before the survey were eligible to be interviewed. In addition, in a sub-sample of half of all the households selected for the survey, all men age 1559 were eligible to be interviewed if they were either permanent residents or visitors present in the household on the night before the survey. Thus, the analysis presented in this study on the impact of Demographic, Socio-economic, and Cultural factors that affect Fertility among women of childbearing age in Ethiopia is based on 10,897 women who have at least one child and whose age ranges from 15 to 49 years.

\subsection{Variables Under Study}

\subsubsection{Dependent/Outcome Variable}

The dependent/response variable is the dichotomous variable "Total Children ever-born (TCEB) of the respondent" (Case $=1$, Control $=0$ ). The selection of this variable is based on its proximity to the concept of individual fertility. Therefore, in these study total children ever born (TCEB) is the dependent variable. The control category (coded as 0) represents women with fewer than five TCEB and the case (coded as 1) represents women with five or more children.

\subsubsection{Explanatory Variables/Factors}

Predicting whether an event will or will not occur and identifying the variables in making the prediction is an important step in carrying out the study. The independent variables/factors that are used in the study were Demographic, Socio-economic, and Cultural factors displayed in table 1 .

\subsection{Methods of Data Analysis}

\subsubsection{The Logistic Regression Model}

Logistic regression is a statistical technique for predicting the probability of an event, given a set of predictor variables. The procedure is more sophisticated than the linear regression procedure. The binary logistic regression procedure empowers one to select the predictive model for dichotomous dependent variables. It describes the relationship between a dichotomous response variable and a set of explanatory variables. The explanatory variables may be continuous or discrete. The logistic model, as a non-linear regression model, is a special case of generalized linear model [8]. For a binary response $Y_{j}$ and quantitative explanatory variable $X_{i j}, i=1,2, \ldots, m$ and $j=1,2, \ldots, n$ let $\pi_{\mathrm{j}}=P\left(X_{i j}\right)$ denote the "success probability" when $\mathrm{X}_{\mathrm{ij}}$ takes the values $X_{i j}$. The problem with linear model is that the probability model $\mathrm{E}(\mathrm{Y})=\mathrm{X} \beta$ (where $\beta$ is the vector of parameters to be estimated) is used to approximate a probability value, $\pi_{\mathrm{j}}=\mathrm{P}\left(\mathrm{Y}_{\mathrm{j}}=1\right)$ within the interval 0 and 1 , while $E\left(Y_{j}=1\right)$ is not so constrained. Therefore, we apply the logit transformation where the transformed quantity $\log \left(\frac{\pi_{\mathrm{j}}}{1-\pi_{\mathrm{j}}}\right)$ lies in the interval $(-\infty, \infty)$ and it is modeled as.

$$
\begin{array}{r}
\operatorname{logit}\left(\pi_{j}\right)=\log \left(\frac{\pi j}{1-\pi j}\right)=\exp \left(\beta_{0}+\beta_{1} x_{1 j}+\beta_{2} x_{2 j}+\beta_{3} x_{3 j}+\cdots+\beta_{k} x_{k j}\right) \\
\pi_{j}=\frac{\exp \left(\beta_{0}+\beta_{1} x_{1 j}+\beta_{2} x_{2 j}+\beta_{3} x_{3 j}+\cdots+\beta_{k} x_{k j}\right)}{1+\exp \left(\beta_{0}+\beta_{1} x_{1 j}+\beta_{2} x_{2 j}+\beta_{3} x_{3 j}+\cdots+\beta_{k} x_{k j}\right)}=\left(\frac{1}{1+\exp \left(-x^{\prime} \beta\right)}\right)
\end{array}
$$

here the parameter $\beta_{\mathrm{i}}$ determines the rate of increase or decrease of $X_{i j}$ on the $\log$ of odds that $Y_{j}=1$, controlling for other X's. Each observation (response) can be considered as an outcome of a Bernoulli trial. Hence for the $\mathrm{j}^{\text {th }}$ observation 
$\mathrm{Y}_{\mathrm{j}}$ the Bernoulli distribution is

$$
\pi\left(Y=y_{j}\right)=\pi^{y_{j}}(1-\pi)^{1-y_{j}}
$$

\subsubsection{Assessing the Goodness of Fit of the Model}

In testing the hypothesis that the model fits the data, the two common approaches are Pearson's $X^{2}$ statistic and the likelihood-ratio statistic $\left(G^{2}\right)$ which are based on the comparison of the fitted and the observed counts. The large values of $X^{2}$ and $G^{2}$ indicate lack of fit of the model. When the fit is poor, residuals and other diagnostic measures describe the influence of individual observations on the model fit and highlight reasons for the inadequacy.

$$
\begin{gathered}
\mathrm{G}^{2}=2 \sum(\text { observed }) \log \left(\frac{\text { observed }}{\text { full }}\right)=-2 L_{\mathrm{R}}-\left(-2 L_{\mathrm{F}}\right) \\
=-2 \ln \left(\frac{\text { Likelihood restricted }}{\text { Likelihood full }}\right)
\end{gathered}
$$

The likelihood ratio is $-2 \ln$ (Likelihood $\mathrm{R}$ ) forare smaller model minus-2ln(likelihood F)forafull (larger) model that is the same as the log of the ratio of the two likelihoods, which is distributed as chi-square. The full or larger model has all the parameters of interest in it.

The chi-square is used to statistically test whether including a variable reduces badness-of-fit measure. This is analogous to producing an increment in R-square in hierarchical regression. If chi-square is significant, the variable is considered to be a significant predictor in the equation.

The Pearson'sX ${ }^{2}$ statistics is given by

$$
X^{2}=\sum_{i=1}^{n} \frac{\left(O_{i}-E_{i}\right)^{2}}{E_{i}}
$$

Where $\mathrm{X}^{2}=$ Pearson's cumulative test statistic, which asymptotically approaches a $\mathrm{X}^{2}$ distribution.

$\mathrm{O}_{\mathrm{i}}=$ an observed frequency;

$E_{i}=$ an expected (theoretical) frequency, asserted by the null hypothesis;

$\mathrm{n}=$ the number of cells in the table.

The Hosmer- Lemeshow test is another alternative in checking model fitness. The test is similar to a $\mathrm{X}^{2}$ goodness of fit test and has the advantage of partitioning the observations into groups of approximately equal size, and therefore there are less likely to be groups with very low observed and expected frequencies. The observations are grouped into deciles based on the predicted probabilities. The test statistic is obtained by applying a chi-square test on $2 x g$ a contingency table. The contingency table is constructed by cross-classifying the dichotomous dependent variable with a grouping variable (with g groups) in which groups are formed by partitioning the predicted probabilities using the percentiles of the predicted event probability. In the calculation, approximately 10 groups are used $(\mathrm{g}=10)$. The corresponding groups are often referred to as the "deciles of risk" [9].

\section{Results}

The major Demographic, Socio-economic, and Cultural background characteristics of the respondents are presented in
Table 2. The total number of women in childbearing age is based on 10,897 women who have at least one child and whose age ranges from 15 to 49 years. Among these, 8130 (74.6\%) reside in rural areas where as 2767 (25.4\%) reside in urban hubs. Among those individuals $64.2 \%$ were currently not working and the remaining $35.8 \%$ of the respondent were categorized under currently working group. In relation to age at first Cohabitation, about $37.7 \%$ of individuals were fail under 15-17 interval of age category and $34.5 \%$ of respondent were greater than or equal to 18 years old. The majority of individuals were married 8621 (79.1\%), followed by divorced and living with partner (716 (6.6\%) and living with partner 588 (5.4\%) respectively). With regard to regional variation of Ethiopia, greater part of respondents included in this study were from Oromiya, Amahara and SNNP (13.5\%, 13\% and 12.5\%) respectively where as smaller part were from Dire Dawa and Somali $(6.1 \%$ and $6.2 \%$ ) respectively. With regard to Women Educational level, $65.80 \%$ were No education, primary were about $26.1 \%$ and the remaining $8.10 \%$ belongs to secondary and above educational level. Results on the respondent religion shows about $66.1 \%$ of Orthodox women were control and the remaining $33.9 \%$ are cases. Women who were Muslim are about $56 \%$ (2452) of the given value categorized under controls and $44 \%$ (1923) cases. Similarly, women who were followers of other religious $53(45.7 \%)$ are controls and 54.3 (63\%). In relation wealth index, the majority of individuals, about $27.1 \%$ were richer, $26.4 \%$ from poorer category and the remaining amount were from other category. About 100\% (421) of Women at the age group 25-29 were categorized under control group which implies that those given less than five live births. A large percentage of women know modern contraception method. Total number of children ever born varies by the demographic, socioeconomic and cultural Characteristic of the individual fertility rate. Table 2, presents all explanatory variables have significant effect on an outcome variable at 5\% level of significant.

\subsection{Assessing the Goodness of Fit of the Model}

Subsequently fitting a model to a set of data, it is natural to enquire about the extent to which the fitted values of the response variable under the model compare with the observed values. If the agreement between the observations and the corresponding fitted values is good, the model may be acceptable. If not, the current form of model will certainly not be acceptable and the model will need to be revised. This aspect of the adequacy of a model is widely referred to as goodness of fit. To determine the overall significance of a logistic model Likelihood Ratio Test, Classification table and Hosmer and Lemeshow goodness-of-fit test were used. In this study, data were analyzed by using statistical software Statistical package for social sciences (SPSS) Version 16.

\subsubsection{Classification Table}

From the classification table (table 3), the overall percentage of those correctly classified is equal to $81.3 \%$. We can inspect the table for some specifics: of the total child ever born, the model correctly classifies 11,815 , or $81.3 \%$. The model predicting Total child ever born case individuals 
correctly classifies 3457 out of 4324. The "Overall Percentage" of $81.3 \%$ is calculated by summing up the diagonal values (5392 and 3457) and dividing over the total number of subjects. The diagonal consist of the sum of " total child ever born Control group" and" Total child ever born case group" frequencies. Therefore, the resulting percentage correctly classifiedis $81.3 \%$. This shows that the final logistic regression model executes well. Using the classification table and the model chi-square goodness fit test we can say the fitted model is statistically significant. In univariate analysis, using Pearson chi square test (Table 2), the variables that are found to be significant are age at first cohabitation (in years), Age in 5-years interval, Husband Educational level, Religion, Residence, Wealth index, Current marital status, Region, Wife Educational Level, ever use of contraceptive method and Mothers Working Status.

\subsubsection{Hosmer and Lemeshow Test}

The Hosmer-Lemeshow test result reported chi-square value of 9.751 with p-value of 0.283 on 8 degrees of freedom. But this p-value is greater than that of 5\% level of significance showing that there is no difference between the observed and the model predicted values and hence, estimates of the model fit the data at an acceptable level. Assessment of the interaction terms showed that none of them were statistically significant and hence were excluded from the model. The Cox and Snell and Nagelkerke pseudo R-square values of the model (Table 4) were 0.416 and 0.563 respectively. Therefore, this statistic provided the same conclusion with above discussion which implied as the model fits data well.

\subsection{Interpretation of the Results of Binary Logistic Regression}

The Results of Binary Logistic Regression as displayed in table 5, the variables that were found to be significant in the multivariate analysis are Region, Women educational level, wealth index, husband's/partner's educational, marital status, age at first cohabitation and age in 5-years group. And this is in effect in line with the results obtained from the univariate analysis. The values of the Wald statistic for individual $\beta$ coefficients support that the estimated values $\left(\widehat{\beta}_{\mathrm{i}}^{\prime} \mathrm{s}\right)$ are significantly different from zero at $\alpha=0.05$ level of significance for all the above selected factors. The estimated coefficients $\left(\widehat{\beta}_{i}^{\prime} s\right)$ for the factors in the final model, their standard error and the odds ratio of each estimated coefficient $\left(\widehat{\beta}_{\mathrm{i}}\right)$ is also given in the following table are obtained by the procedures of Forward Stepwise (Likelihood Ratio). The final logistic regression model includes only those significant variables. From the fitted logistic regression model, the estimates odds ratio displayed in table 5, for the variable region reference category is Addis Ababa. The value of the odds ratio $\exp (\widehat{\beta})=1.384$, for region that the odds of having TCEB greater than or equals to five children for Tigray region is have $38.4 \%$ more than those individuals in Addis $\operatorname{Ababa}(O R=1.384, C . I=1.055-1.810)$ and its effect is statistically significant. The odds of TCEB greater than or equals to five has decreased by a factor of 0.861 for individuals living in Amhara compared to those in Addis Ababa controlling for other variables in the model. The likelihood of TCEB having greater than or equals to five children is five times more likely for women who have no education; women with primary education $(O R=$ $3.144, C . I=1.692-5.843)$ more than three times more likely to have five or more children in their life time compared with women higher educational level. Women poorer and rich wealth status were about twice more likely for individual with richer wealth status and the odds of TCEB having greater than or equals to five children is about $84.5 \%$ higher $(O R=1.845, C . I=1.517-2.244)$ among women whose wealth status poor controlling other variables in the model constant. The odds of having TCEB greater than or equals to five for husband's/partner's with primary educational level were about $37.5 \%$ less likely to TCEB five or more than five $(O R=0.625, C . I=0.0 .159-2.460)$ than no education. Similarly, the odds of women with TCEB greater than or equals to five were $53.8 \% \quad(O R=$ $0.462, C . I=0.117-1.821) \quad$ and $\quad 60.8 \% \quad(O R=$ $0.392, C . I=0.098-1.559$ ) less likely women with primary and secondary education compared with higher educational level respectively.

\section{Discussion}

The finding of this study illustrates the TCEB is significantly superior among women who have no education and primary education. A similar study carried out in Nepal indicated that education exposes women to information, empowers women, makes them more likely to be employed outside their home environment, and makes them more aware of their own health and the health of their children. Educated women are more likely to postpone marriage, have smaller family size, and use contraception than are uneducated women [10].

The finding of this study shows that residential differences had a significant impact on TCEB. Women who lived in rural $(74.6 \%)$ areas were more likely to have more children than urban $(25.4 \%)$ women. This finding corresponds with the result of a study in Nepal where they show that rural women wish to have more children than urban women [11]. The difference in wish for additional children among rural and urban women could be due to the parents' perceived costs and benefits of children.

Other similar study conducted in Pakistan shows that fertility is lower in urban areas than in rural areas due to the impact of a host of factors [12]. The result of this study shows that women married to husbands with illiterate, primary and secondary education are likely to have five or more CEB than those married to husbands with higher education. A similar study done Bangladesh also shows that husbands who had secondary or higher education were less likely to desire for additional children than those who had no education. Traditional attitude, beliefs and norms can overcome the education, which may lead the women to have birth until the desire sex compositions of children are met. If a husband would like to have a big family, then a woman has to follow his wish [13].

According to this research finding religion has been found 
to have a significant effect on TCEB. Results on the respondent religion shows about $66.1 \%$ of Orthodox women were control and the remaining $33.9 \%$ are cases. Women who were Muslim are about $56 \%$ (2452) of the given value categorized under controls and 44\% (1923) cases. Similarly, women who were followers of other religious 53 (45.7\%) are controls and $54.3(63 \%)$. In addition, the age in group of women is a statistically significant variable that can affect TCEB. Women whose age is in between 20-24 are less likely to have five or more children than women whose age in between 40-45. A similar study also shows that teenagers whose age was between 18 and 19 years were about eight times more likely to be fertile than young people whose age between 15-17 years. As the age increases, the risk of disclosure to pregnancy and childbearing also increases, because of higher probability of getting sexual relation and marriage [14]. With regard to regional variations, TCEB is highest in Oromiya (13.5 percent) and Amhara (13 percent) followed by SNNPR and Tigray (12.5 and 10.8 percent) respectively. Working status of an individual is another important explanatory variable affecting TCEB of an individual. The finding of this study shows that respondents currently not working (41.6 percent) are more likely to fertile greater than or equals to five children than individuals who are working (36.4 percent) as presented in table 2 .

\section{Conclusion}

This study is undertaken to identify Demographic, Socioeconomic, and Cultural factors that affect Fertility level among women of childbearing age in Ethiopia. Data from the Ethiopia Demographic and Health Survey (EDHS) 2011 are used for analysis.

Based on the result of Univariate analysis, using Pearson chi square test (Table 2), the variables that are found to be significant are age at first cohabitation (in years), Age in 5-years interval, Husband Educational level, Religion, Residence, Wealth index, Current marital status, Region, Wife Educational Level, Ever use of contraceptive method and Mothers Working Status have significant effect on TCEB greater than or equals to five children at 5\% level of significance. From the fitted logistic regression model, the estimates odds ratio displayed in table 5, for the variable region reference category is Addis Ababa. The value of the odds ratio $\exp (\widehat{\beta})=1.384$, for region that the odds of having TCEB greater than or equals to five children for Tigray region is have $38.4 \%$ more than those individuals in Addis Ababa $(O R=1.384, C . I=1.055-1.810)$ and its effect is statistically significant. The odds of TCEB greater than or equals to five has decreased by a factor of 0.861 for individuals living in Amhara compared to those in Addis Ababa controlling for other variables in the model. The likelihood of TCEB having greater than or equals to five children is five times more likely for women who have no education; women with primary education $(O R=$ $3.144, C . I=1.692-5.843)$ more than three times more likely to have five or more children in their life time compared with women higher educational level.

\section{Acknowledgements}

The author thanks Ethiopian Central Statistical Agency for providing access to the data.

\section{Appendix}

Table 1. Explanatory variables included in the analyses.

\begin{tabular}{|c|c|c|c|}
\hline S.No. & Variables & Category & Representation \\
\hline 1 & Total children ever born & $\begin{array}{l}\text { Control } \\
\text { Case }\end{array}$ & $Y$ \\
\hline 2 & Age at first marriage (in years) & $\begin{array}{l}15-17 \\
\text { More than or equals to } 18\end{array}$ & $\mathrm{X}_{1}$ \\
\hline 3 & Age in 5-years interval & $\begin{array}{l}15-19 \\
20-24 \\
25-29 \\
30-34 \\
35-39 \\
40-44 \\
45-49\end{array}$ & $\mathrm{X}_{2}$ \\
\hline 4 & Residence & $\begin{array}{l}\text { Urban } \\
\text { Rural }\end{array}$ & $\mathrm{X}_{3}$ \\
\hline 5 & Religion & $\begin{array}{l}\text { Orthodox } \\
\text { Protestant } \\
\text { Muslim } \\
\text { Catholic } \\
\text { Others }\end{array}$ & $\mathrm{X}_{4}$ \\
\hline 6 & Husband Educational Level & $\begin{array}{l}\text { Illiterate } \\
\text { Primary } \\
\text { Secondary } \\
\text { Above Secondary }\end{array}$ & $\mathrm{X}_{5}$ \\
\hline 7 & Mother's Working Status & $\begin{array}{l}\text { Not working (housewife) } \\
\text { Working }\end{array}$ & $\mathrm{X}_{6}$ \\
\hline
\end{tabular}




\begin{tabular}{|c|c|c|c|}
\hline S.No. & Variables & Category & Representation \\
\hline 8 & Ever use of contraceptive method & $\begin{array}{l}\text { Never used } \\
\text { Ever used }\end{array}$ & $\mathrm{X}_{7}$ \\
\hline 9 & Wife Educational Level & $\begin{array}{l}\text { Illiterate } \\
\text { Primary } \\
\text { Secondary } \\
\text { Above Secondary }\end{array}$ & $\mathrm{X}_{8}$ \\
\hline 10 & Region & $\begin{array}{l}\text { Tigray } \\
\text { Affar } \\
\text { Amhara } \\
\text { Oromiya } \\
\text { Somali } \\
\text { Benishangul-Gumuz } \\
\text { SNNPR } \\
\text { Gambela } \\
\text { Harari } \\
\text { Addis Ababa } \\
\text { Dire Dawa }\end{array}$ & $\mathrm{X}_{9}$ \\
\hline 11 & Wealth index & $\begin{array}{l}\text { Poorer } \\
\text { Poor } \\
\text { Middle } \\
\text { Rich } \\
\text { Richer }\end{array}$ & $\mathrm{X}_{10}$ \\
\hline 12 & Currentmaritalstatus & $\begin{array}{l}\text { Never in union } \\
\text { Married } \\
\text { Living with partner } \\
\text { Widowed } \\
\text { Divorced } \\
\text { Separated }\end{array}$ & $\mathrm{X}_{11}$ \\
\hline
\end{tabular}

Table 2. Crosstabulation of Responsevariable with Predictorvariables.

\begin{tabular}{|c|c|c|c|c|c|c|c|}
\hline \multirow{3}{*}{ Variables } & \multirow{3}{*}{ Category } & \multirow{3}{*}{$\begin{array}{l}\text { Frequency( } \\
\%)\end{array}$} & \multicolumn{4}{|c|}{ Fertility among women of childbearing age } & \multirow{3}{*}{$\begin{array}{l}X^{2} \\
(\text { PValue })\end{array}$} \\
\hline & & & \multicolumn{2}{|l|}{ Control } & \multicolumn{2}{|l|}{ Case } & \\
\hline & & & Count & RowN\% & Count & RowN\% & \\
\hline \multirow{10}{*}{ Region } & Tigray & $1173(10.8)$ & 677 & 57.7 & 496 & 42.3 & \multirow{10}{*}{0.000} \\
\hline & Affar & $944(8.7)$ & 530 & 56.1 & 414 & 43.9 & \\
\hline & Amhara & $1415(13)$ & 805 & 56.9 & 610 & 43.1 & \\
\hline & Oromiya & $1470(13.5)$ & 848 & 57.7 & 622 & 42.3 & \\
\hline & Somali & $678(6.2)$ & 308 & 45.4 & 370 & 54.6 & \\
\hline & SNNPR & $1358(12.5)$ & 679 & 50.0 & 679 & 50.0 & \\
\hline & Gambela & $832(7.6)$ & 556 & 66.8 & 276 & 33.2 & \\
\hline & Harari & $695(6.4)$ & 499 & 71.8 & 196 & 28.2 & \\
\hline & Addis Ababa & $746(6.8)$ & 665 & 89.1 & 81 & 10.9 & \\
\hline & Dire Dawa & $670(6.1)$ & 478 & 71.3 & 192 & 28.7 & \\
\hline \multirow{2}{*}{ Place of Residence } & Urban & $2767(25.4)$ & 2227 & 80.5 & 540 & 19.5 & \multirow{2}{*}{0.0000} \\
\hline & Rural & $8130(74.6)$ & 4341 & 53.4 & 3789 & 46.4 & \\
\hline \multirow{2}{*}{$\begin{array}{l}\text { Highest educational } \\
\text { level }\end{array}$} & Secondary education & $556(5.1)$ & 529 & 95.1 & 27 & 4.9 & \multirow{2}{*}{0.000} \\
\hline & Higher & $325(3.0)$ & 311 & 95.7 & 14 & 4.3 & \\
\hline \multirow{6}{*}{ Religion } & Orthodox & $4232(38.8)$ & 2797 & 66.1 & 1435 & 33.9 & \\
\hline & Catholic & $123(1.1)$ & 67 & 54.5 & 56 & 45.5 & \\
\hline & Protestant & $1975(18.1)$ & 1159 & 58.7 & 816 & 41.3 & \\
\hline & Muslim & $4375(40.1)$ & 2452 & 56.0 & 1923 & 44.0 & \\
\hline & Traditional & $76(0.7)$ & 40 & 52.6 & 36 & 47.4 & \\
\hline & Others & $116(1.1)$ & 53 & 45.7 & 63 & 54.3 & \\
\hline \multirow{5}{*}{ Wealth index } & Poorer & $2882(26.4)$ & 1461 & 50.7 & 1421 & 49.3 & \multirow{5}{*}{0.000} \\
\hline & Poor & $1761(16.2)$ & 935 & 53.1 & 826 & 46.9 & \\
\hline & Middle & $1637(15.0)$ & 866 & 52.9 & 771 & 47.1 & \\
\hline & Rich & $1663(15.3)$ & 932 & 56.0 & 731 & 54.0 & \\
\hline & Richer & $2954(27.1)$ & 2374 & 80.4 & 580 & 19.6 & \\
\hline & Knows no method & $574(5.3)$ & 274 & 48.4 & 296 & 51.6 & \multirow{2}{*}{0.000} \\
\hline Knowledge of any & Knows only folkloric method & $1(0)$ & 0 & 0 & 1 & 100 & \\
\hline Currently working & No & $6986(64.2)$ & 4083 & 58.4 & 2903 & 41.6 & 0.000 \\
\hline
\end{tabular}




\begin{tabular}{|c|c|c|c|c|c|c|c|}
\hline \multirow{3}{*}{ Variables } & \multirow{3}{*}{ Category } & \multirow{3}{*}{$\begin{array}{l}\text { Frequency( } \\
\%)\end{array}$} & \multicolumn{4}{|c|}{ Fertility among women of childbearing age } & \multirow{3}{*}{$\begin{array}{l}X^{2} \\
(\text { PValue })\end{array}$} \\
\hline & & & \multicolumn{2}{|l|}{ Control } & \multicolumn{2}{|l|}{ Case } & \\
\hline & & & Count & RowN\% & Count & RowN\% & \\
\hline \multirow[t]{4}{*}{ status } & Yes & $3899(35.8)$ & 2478 & 63.6 & 1421 & 36.4 & \\
\hline & Never in union & $103(0.9)$ & 102 & 99.0 & 1 & 1 & \\
\hline & Married & $8621(79.1)$ & 4965 & 57.6 & 3656 & 42.4 & \\
\hline & Living with partner & $588(5.4)$ & 424 & 72.1 & 164 & 27.9 & \\
\hline \multirow[t]{3}{*}{ Current marital status } & Widowed & $561(5.1)$ & 262 & 46.7 & 299 & 53.3 & 0.000 \\
\hline & Divorced & $716(6.6)$ & 561 & 78.4 & 155 & 21.6 & \\
\hline & $\begin{array}{l}\text { No longer living } \\
\text { together/separated }\end{array}$ & $308(2.8)$ & 254 & 82.5 & 54 & 17.5 & \\
\hline \multirow{3}{*}{$\begin{array}{l}\text { Age at first } \\
\text { cohabitation }\end{array}$} & Below15years & $3029(27.8)$ & 1481 & 48.9 & 1548 & 51.1 & \multirow{3}{*}{0.000} \\
\hline & $15-17$ & $4105(37.7)$ & 2411 & 58.7 & 1694 & 41.3 & \\
\hline & Above18years & $3763(34.5)$ & 2676 & 71.1 & 1087 & 28.9 & \\
\hline \multirow{7}{*}{ Agein5-yearsgroup } & $15-19$ & $421(3.9)$ & 421 & 100 & 0 & 0 & \multirow{7}{*}{0.000} \\
\hline & $20-24$ & $1674(15.4)$ & 1645 & 98.3 & 29 & 1.7 & \\
\hline & $25-29$ & $2665(24.5)$ & 2245 & 84.2 & 420 & 15.8 & \\
\hline & $30-34$ & $1937(17.8)$ & 1053 & 54.4 & 884 & 45.6 & \\
\hline & $35-39$ & $1860(17.1)$ & 664 & 35.7 & 1196 & 64.3 & \\
\hline & $40-44$ & $1275(11.7)$ & 331 & 26.0 & 944 & 74.0 & \\
\hline & $45-49$ & $1065(9.8)$ & 209 & 19.6 & 856 & 80.4 & \\
\hline \multirow{4}{*}{$\begin{array}{l}\text { Husband/partners } \\
\text { educational level }\end{array}$} & No education & $5408(49.6)$ & 2646 & 48.9 & 2762 & 51.1 & \multirow{4}{*}{0.000} \\
\hline & Primary education & $3632(33.3)$ & 2348 & 64.6 & 1284 & 35.4 & \\
\hline & Secondary education & $970(8.9)$ & 806 & 83.1 & 134 & 16.9 & \\
\hline & Higher & $887(8.1)$ & 768 & 86.6 & 119 & 13.4 & \\
\hline
\end{tabular}

Table 3. Classification Table.

\begin{tabular}{|c|c|c|c|c|}
\hline \multirow{3}{*}{ Observed } & & \multicolumn{3}{|c|}{ Predicted } \\
\hline & & \multicolumn{2}{|c|}{ Total child ever born } & \multirow{2}{*}{ Percentage correct } \\
\hline & & Control & Case & \\
\hline \multirow{2}{*}{ Total child ever born } & Control & 5392 & 1169 & 82.2 \\
\hline & Case & 867 & 3457 & 79.9 \\
\hline Overall percentage & & & & 81.3 \\
\hline
\end{tabular}

a. The cut value is 0.500 .

Table 4. Hosmerandleme show test.

\begin{tabular}{llll}
\hline Chi-square & Df & Sig. & \\
\hline 9.751 & 8 & .283 & \\
\hline
\end{tabular}

Table 5. Results of binarylogisticregression.

\begin{tabular}{|c|c|c|c|c|c|c|c|c|c|}
\hline & \multirow{2}{*}{ Category } & \multirow{2}{*}{ B } & \multirow{2}{*}{ S.E. } & \multirow{2}{*}{ Wald } & \multirow{2}{*}{ Df } & \multirow{2}{*}{ Sig. } & \multirow{2}{*}{$\operatorname{Exp}(B)$} & \multicolumn{2}{|c|}{ 95.0\%C.I.forEXP(B) } \\
\hline & & & & & & & & Lower & Upper \\
\hline \multirow{11}{*}{ Region } & Region & & & 149.453 & 10 & .000 & & & \\
\hline & Tigray & .325 & .139 & 5.492 & 1 & .019 & 1.384 & 1.055 & 1.817 \\
\hline & Affar & .112 & .146 & .591 & 1 & .442 & 1.118 & .841 & 1.488 \\
\hline & Amhara & -.149 & .135 & 1.213 & 1 & .271 & .861 & .661 & 1.123 \\
\hline & Oromiya & .377 & .133 & 8.100 & 1 & .004 & 1.459 & 1.125 & 1.891 \\
\hline & Somali & .897 & .152 & 34.957 & 1 & .000 & 2.453 & 1.822 & 3.302 \\
\hline & SNNPR & .731 & .134 & 29.877 & 1 & .000 & 2.078 & 1.598 & 2.700 \\
\hline & Gambela & .010 & .151 & .005 & 1 & .945 & 1.011 & .751 & 1.359 \\
\hline & Harari & .109 & .154 & .500 & 1 & .480 & 1.115 & .824 & 1.509 \\
\hline & Addis Ababa & -.497 & .178 & 7.775 & 1 & .005 & .608 & .429 & .863 \\
\hline & Dire Dawa(Ref.) & - & - & - & - & - & - & - & - \\
\hline \multirow{3}{*}{$\begin{array}{l}\text { Mother's } \\
\text { Educational } \\
\text { level }\end{array}$} & Edu Level & & & 96.339 & 3 & .000 & & & \\
\hline & No education & 1.642 & .320 & 26.383 & 1 & .000 & 5.167 & 2.761 & 9.670 \\
\hline & Higher(Ref.) & - & - & - & - & - & - & - & - \\
\hline \multirow{6}{*}{ Wealth index } & V190WealthIndex & & & 71.734 & 4 & .000 & & & \\
\hline & Poorer & .764 & .095 & 64.496 & 1 & .000 & 2.147 & 1.782 & 2.587 \\
\hline & Poor & .612 & .100 & 37.560 & 1 & .000 & 1.845 & 1.517 & 2.244 \\
\hline & Middle & .700 & .101 & 47.889 & 1 & .000 & 2.015 & 1.652 & 2.457 \\
\hline & Rich & .599 & .098 & 37.176 & 1 & .000 & 1.820 & 1.502 & 2.207 \\
\hline & Richer(Ref.) & - & - & - & - & - & - & - & - \\
\hline
\end{tabular}




\begin{tabular}{|c|c|c|c|c|c|c|c|c|c|}
\hline & \multirow{2}{*}{ Category } & \multirow{2}{*}{ B } & \multirow{2}{*}{ S.E. } & \multirow{2}{*}{ Wald } & \multirow{2}{*}{ Df } & \multirow{2}{*}{ Sig. } & \multirow{2}{*}{$\operatorname{Exp}(B)$} & \multicolumn{2}{|c|}{ 95.0\%C.I.forEXP(B) } \\
\hline & & & & & & & & Lower & Upper \\
\hline \multirow{8}{*}{$\begin{array}{l}\text { Husband's } \\
\text { educational } \\
\text { level }\end{array}$} & Husband edu Level & & & 39.999 & 5 & .000 & & & \\
\hline & No education(Ref.) & - & - & - & - & - & - & - & - \\
\hline & Primary education & -.470 & .699 & .452 & 1 & .501 & .625 & .159 & 2.460 \\
\hline & Secondary education & -.771 & .699 & 1.216 & 1 & .270 & .462 & .117 & 1.821 \\
\hline & Higher & -.937 & .705 & 1.768 & 1 & .184 & .392 & .098 & 1.559 \\
\hline & marital status & & & 97.844 & 5 & .000 & & & \\
\hline & Never in union & -3.155 & 1.251 & 6.364 & 1 & .012 & .043 & .004 & .495 \\
\hline & Married & .768 & .190 & 16.298 & 1 & .000 & 2.157 & 1.485 & 3.132 \\
\hline \multirow[t]{5}{*}{ Marital status } & Living with partner & .334 & .224 & 2.220 & 1 & .136 & 1.397 & .900 & 2.169 \\
\hline & Widowed & 1.200 & .219 & 30.058 & 1 & .000 & 3.321 & 2.162 & 5.101 \\
\hline & Divorced & -.049 & .221 & .050 & 1 & .823 & .952 & .618 & 1.467 \\
\hline & Separated (Ref.) & - & - & - & - & - & - & - & - \\
\hline & Age at first cohabitation & & & 139.776 & 2 & .000 & & & \\
\hline \multirow{6}{*}{$\begin{array}{l}\text { Age at } \\
\text { cohabitation }\end{array}$} & Below15years & .852 & .072 & 139.701 & 1 & .000 & 2.345 & 2.036 & 2.701 \\
\hline & $15-17$ & .389 & .065 & 36.258 & 1 & .000 & 1.475 & 1.300 & 1.675 \\
\hline & Above 18 years (Ref.) & - & - & - & - & - & - & - & - \\
\hline & Age in 5-years group & & & $1.977 \mathrm{E} 3$ & 6 & .000 & & & \\
\hline & $15-19$ & -22.516 & $1.852 \mathrm{E} 3$ & .000 & 1 & .990 & .000 & .000 & . \\
\hline & $20-24$ & -5.440 & .208 & 687.358 & 1 & .000 & .004 & .003 & .007 \\
\hline \multirow{6}{*}{$\begin{array}{l}\text { Age in } 5- \\
\text { years group }\end{array}$} & $25-29$ & -3.100 & .103 & 914.721 & 1 & .000 & .045 & .037 & .055 \\
\hline & $30-34$ & -1.508 & .099 & 231.610 & 1 & .000 & .221 & .182 & .269 \\
\hline & $35-39$ & -.736 & .101 & 53.112 & 1 & .000 & .479 & .393 & .584 \\
\hline & $40-44$ & -.309 & .111 & 7.782 & 1 & .005 & .734 & .591 & .912 \\
\hline & 45-49(Ref.) & - & - & - & - & - & - & - & - \\
\hline & Constant & -1.291 & .788 & 2.684 & 1 & .101 & .275 & & \\
\hline
\end{tabular}

a. Variable(s) entered on step 1: Mother's educational level

b. Variable(s) entered on step 2: Husband's educational level

c. Variable(s) entered on step 3: Wealth Index.

d. Variable(s) entered on step 4: Age at cohabitation

e. Variable(s) entered on step 5: Region

f. Variable(s) entered on step 6: Marital status.

g. Variable(s) entered on step 7: Age in 5years group

\section{References}

[1] Caldwell J.C and Caldwell P. 1987. The cultural context of high fertility in sub-sharan Africa. Population and Development Review 13(3): 409-437.

[2] Oluwayemisi O Alaba, Olusanya E Olubusoye \& JO Olaomi (2017) Spatial patterns and determinants of fertility levels among women of childbearing age in Nigeria, South African Family Practice, 59:4, 143-147.

[3] Dieudonne Ndaruhuye Muhoza, Annelet Broekhuis,and Pieter Hooimeijer. Variations in Desired Family Size and Excess Fertility in East Africa. International Journal of Population Research Volume 2014, Article ID 486079.

[4] Tewodros T. Cross Sectional Study of Women Employment and Fertility in Ethiopia, 2011; 1-63.

[5] Yohannes F., Yimane B., Alemayehu W. Impact of Child Mortality and Fertility on Fertility Status in Rural Ethiopia. East Africa Medical Journal, 2004.81(6): 301-305.

[6] Samson Gebremedhin and MulugetaBetre, Level and Differentials of Fertility in Hwassa Town, Southern Ethiopia, 2009: Afr J Reprod Health 13(1):93-112.

[7] CSA (2011). Ethiopia Demographic and Health Survey Reports. Addis Ababa, Ethiopia.

[8] McCullagh, P. and Nelder, J. A. (1989) Generalized Linear Models, Chapman and Hall, London.

[9] Hosmer, D.W., S. Taber and S. Lemeshow (1991). The Importance Assessing the Fit of Logistic Regression Models: A Case Study. Am. J. Public Health, 81: 1630-1635.

[10] R Ramesh A. 2010. Demographic, socio-economic and cultural factors affecting fertility differential in Nepal. Geography and Population Department, Tribhuvan Universty, Kathmndul, Nepal.

[11] Sharma S. 1998. Relationship between gender of existing children and desire for additional children by Nepalese women. Master's Thesis, Institute for Population and Social Research, Mahidol University.

[12] Abdul Hakim, 1994.Factors affecting fertility in Pakistan. The Pakistan Development Review 33(4): 685-709

[13] Mokshed, Ali 2000. The effect of selected socio-demographic characteristics on desire for additional children among couples in Bangladesh. Mahidol Universty.

[14] Tewodros Alemayehu, Jemal Haider and Dereje Habte 2010. Determinants of adolescent fertility in Ethiopia. Ethiop. J. Health Dev. 24(1):30-38. 